University of Nebraska - Lincoln

DigitalCommons@University of Nebraska - Lincoln

USDA Forest Service / UNL Faculty Publications U.S. Department of Agriculture: Forest Service -National Agroforestry Center

2012

Estimating aboveground carbon stocks of a forest affected by mountain pine beetle in Idaho using lidar and multispectral imagery

\author{
Benjamin C. Bright \\ University of Idaho, bright@uidaho.edu \\ Jeffrey A. Hicke \\ University of Idaho, jhicke@uidaho.edu \\ Andrew T. Hudak \\ Rocky Mountain Research Station, ahudak@fs.fed.us
}

Follow this and additional works at: https://digitalcommons.unl.edu/usdafsfacpub

Bright, Benjamin C.; Hicke, Jeffrey A.; and Hudak, Andrew T., "Estimating aboveground carbon stocks of a forest affected by mountain pine beetle in Idaho using lidar and multispectral imagery" (2012). USDA Forest Service / UNL Faculty Publications. 215. https://digitalcommons.unl.edu/usdafsfacpub/215

This Article is brought to you for free and open access by the U.S. Department of Agriculture: Forest Service -National Agroforestry Center at DigitalCommons@University of Nebraska - Lincoln. It has been accepted for inclusion in USDA Forest Service / UNL Faculty Publications by an authorized administrator of DigitalCommons@University of Nebraska - Lincoln. 


\title{
Estimating aboveground carbon stocks of a forest affected by mountain pine beetle in Idaho using lidar and multispectral imagery
}

\author{
Benjamin C. Bright ${ }^{\text {a,* }}$, Jeffrey A. Hicke ${ }^{a}$, Andrew T. Hudak ${ }^{b}$ \\ a University of Idaho, Department of Geography, 810 W 7th Street, McClure Hall 203, Moscow, ID 83844, USA \\ ${ }^{\mathrm{b}}$ USDA Forest Service, Rocky Mountain Research Station, 1221 South Main Street, Moscow, ID 83843, USA
}

\section{A R T I C L E I N F O}

Article history:

Received 8 March 2012

Received in revised form 17 May 2012

Accepted 19 May 2012

Available online 15 June 2012

\section{Keywords:}

Carbon

Mountain pine beetle

Insect outbreak

Tree mortality

Aerial imagery

Lidar

\begin{abstract}
A B S T R A C T
Mountain pine beetle outbreaks have caused widespread tree mortality in North American forests in recent decades, yet few studies have documented impacts on carbon cycling. In particular, landscape scales intermediate between stands and regions have not been well studied. Remote sensing is an effective tool for quantifying impacts of insect outbreaks on forest ecosystems at landscape scales. In this study, we developed and evaluated methodologies for quantifying aboveground carbon (AGC) stocks affected by mountain pine beetle using field observations, lidar data, and multispectral imagery. We evaluated methods at two scales, the plot level and the tree level, to ascertain the capability of each for mapping AGC impacts of bark beetle infestation across a forested landscape. In 27 plots across our 5054-ha study area in central Idaho, we measured tree locations, health, diameter, height, and other relevant attributes. We used allometric equations to estimate AGC content of individual trees and, in turn, summed tree AGC estimates to the plot level. Tree-level and plot-level AGC were then predicted from lidar metrics using separate statistical models. At the tree level, cross-validated additive models explained $50-54 \%$ of the variation in tree AGC (root mean square error (RMSE) values of $26-42 \mathrm{~kg}$ AGC, or $32-48 \%$ ). At the plot level, a cross-validated linear model explained $84 \%$ of the variation in plot AGC (RMSE of $9.2 \mathrm{Mg} \mathrm{AGC/ha,} \mathrm{or} \mathrm{12 \% ).} \mathrm{To} \mathrm{map} \mathrm{beetle-caused} \mathrm{tree} \mathrm{mortality,} \mathrm{we} \mathrm{classified} \mathrm{high-resolution} \mathrm{digital} \mathrm{aerial} \mathrm{photog-}$ raphy into green, red, and gray tree classes with an overall accuracy of $87 \%$ (kappa $=0.79$ ) compared with our field observations. We then combined the multispectral classification with lidar-derived AGC estimates to quantify the amount of AGC within beetle-killed trees at the field plots. Errors in classification, apparent tree lean caused by off-nadir aerial imagery, and a bias between percent cover and percent AGC reduced accuracy when combining multispectral and lidar products. Plot-level models estimated total plot AGC more accurately than tree-level models summed for plots as determined by RMSE ( 9.2 versus $21 \mathrm{Mg}$ AGC/ha, respectively) and mean bias error ( 0.52 versus $-6.7 \mathrm{Mg} \mathrm{AGC/ha,} \mathrm{respectively).} \mathrm{When} \mathrm{considering} \mathrm{individual} \mathrm{tree} \mathrm{classes} \mathrm{(green,} \mathrm{red,} \mathrm{gray)} \mathrm{summed} \mathrm{for}$ plots, comparisons of plot-level and tree-level methods exhibited mixed results, with some accuracy measures higher for plot-level models. Despite a lack of clear improvement in tree-level models, we suggest that treelevel models should be considered for assessing situations with high spatial variability such as beetle outbreaks, especially if apparent tree lean effects can be minimized such as through the use of satellite imagery. Our methods illustrate the utility of combining lidar and multispectral imagery and can guide decisions about spatial resolution of analysis for understanding and documenting impacts of these forest disturbances.
\end{abstract}

(C) 2012 Elsevier Inc. All rights reserved.

\section{Introduction}

Outbreaks of the mountain pine beetle (Dendroctonus ponderosae Hopkins) have caused extensive tree mortality throughout British Columbia and the western United States in the last decade (USDA Forest Service, 2010; Westfall \& Ebata, 2011). By killing large numbers of trees, bark beetle outbreaks affect carbon cycling of forest ecosystems (Hicke et al., 2012; Kurz et al., 2008; Stinson et al., 2011). Net primary productivity of forests affected by bark beetle outbreaks is reduced

\footnotetext{
* Corresponding author. Tel.: +1208 8852970.

E-mail address: bright@uidaho.edu (B.C. Bright).
}

when killed trees stop photosynthesizing (Brown et al., 2010; Pfeifer et al., 2011). Remaining vegetation responds to reduced competition for light, water, and nutrients by increasing growth (Romme et al., 1986; Stone \& Wolfe, 1996). After killed trees fall and decay, heterotrophic respiration increases (Edburg et al., 2011). When outbreaks are severe, reduced net primary productivity and increased heterotrophic respiration can cause forests to become carbon sources to the atmosphere (Edburg et al., 2011; Kurz et al, 2008). In recent decades, the impact of insects on carbon cycling has exceeded that of fire in Canada (Kurz \& Apps, 1999; Stinson et al., 2011).

The effect of bark beetle outbreaks on aboveground carbon (AGC) stocks at the landscape-scale is not well understood. Estimates of bark beetle impacts on AGC stocks derived from aerial surveys have been 
used for regional-scale analyses, but are only coarse estimates of mortality at landscape scales (Kurz et al., 2008; Stinson et al., 2011; Walton, 2011). Plot- and stand-scale measurements show great variation in the amount of AGC affected by bark beetles (Pfeifer et al., 2011; Romme et al., 1986), leading to substantial impacts on carbon cycling (Edburg et al., 2011). In the absence of a stratification of the landscape ensuring a representative sample of mortality severity and AGC, plot-level sampling might not be appropriate for estimating landscape-scale effects because beetle-caused tree mortality across landscapes is usually heterogeneous and patchy (Westfall \& Ebata, 2011).

The primary host of the mountain pine beetle is lodgepole pine (Pinus contorta Dougl. ex Loud.), although other pine species are also frequently infested as well (Amman et al., 1990). Pines killed by mountain pine beetles progress through several postoutbreak attack stages (Amman et al., 1990; Hopkins, 1970; Wulder et al., 2006). After trees are attacked and killed in the late summer, tree needles remain green for several months ("green-attack"). In the spring and early summer following death, needles begin to fade from green to red as needles desiccate and lose chlorophyll pigment. About a year after attack all remaining needles turn red and trees enter the red stage. After 3-5 years, most red needles have fallen and only branches remain on the trees in what is called the gray stage. Trees begin falling thereafter, although trees often remain standing for a decade or longer after death (Mitchell \& Preisler, 1998).

Given the high degree of spatial variability in beetle-caused tree mortality within an outbreak area, remote sensing is well suited for documenting landscape-scale impacts. Multispectral remote sensing is an effective tool for mapping the red stage of forest mortality caused by mountain pine beetle outbreaks (Coops et al., 2006; Franklin et al., 2003; Hicke \& Logan, 2009; Meddens et al., 2011; White et al., 2005). Spatial resolutions range from $0.3-30 \mathrm{~m}$, and typical bands used are green, red, and near-infrared. Fine-resolution multispectral sensors can also detect the gray stage of forest mortality (Dennison et al., 2010; Meddens et al., 2011). Detection of the green-attack stage of forest mortality has proven difficult and has not been demonstrated (Wulder et al., 2009).

Light Detection and Ranging (lidar) is a useful method for estimating aboveground forest biomass (e.g., Hall et al., 2005; Naesset \& Gobakken, 2008; Nelson et al., 1988). Lidar metrics have been related to aboveground tree biomass (hereafter referred to as "biomass"), which is itself estimated by applying allometric equations to field measurements of tree stem diameter and sometimes height (García et al., 2010; Popescu, 2007). Resulting regression models can then be applied to map biomass across areas where lidar data have been acquired (Hudak et al., 2006; Y. Kim et al., 2009). Multispectral imagery can be combined with lidar data to separate biomass by forest type (Popescu et al., 2004; Zhao et al., 2009). These methods can also be used to estimate volume in bark beetle-killed trees (Bater et al., 2010). Models relating biomass to lidar metrics are often created at the plot level, but individual tree biomass and tree diameter can also be related to lidar metrics created at the scale of individual tree crowns (e.g., Heurich, 2008; Hyyppa et al., 2001; Persson et al., 2002; Popescu, 2007).

In this study, we developed and evaluated methodologies for quantifying AGC stocks affected by bark beetle outbreaks using field observations, lidar, and multispectral remote sensing. We (1) classified multispectral imagery into green (including healthy and greenattack trees), red, and gray tree classes; (2) developed statistical models relating AGC to lidar metrics; (3) applied statistical models to predict AGC at the field plots; and (4) combined the mortality classification and AGC imagery at the plots to estimate AGC in killed trees (Fig. 1). We compared tree- and plot-level models of AGC. Tree-level models allowed us to map AGC variability at the same resolution as mortality variability, whereas plot-level models are more commonly used. Our study differs from previous studies because (1) we studied AGC stocks rather than volume; (2) we evaluated inaccuracies caused by combining lidar and multispectral imagery; and (3) we evaluated tree- and plot-level models.

\section{Methods}

\subsection{Study area}

The study area is a 5054-ha, mostly forested area located in central Idaho, just north of the town of Stanley, Idaho, USA at $44.3^{\circ} \mathrm{N}, 115.1^{\circ} \mathrm{W}$ (Fig. 2). A mountain pine beetle outbreak began in 2002 in the area and was ongoing in the summer of 2010, although few recently attacked trees were observed in the field, suggesting that the outbreak was subsiding within our study area. Elevation ranges between $1946 \mathrm{~m}$ and $2150 \mathrm{~m}$. We chose an area that is fairly level to minimize slope effects, georegistration errors, and illumination differences on lidar data and multispectral imagery. The forest is dominated by lodgepole pine, with a few other trees species that include Douglas-fir (Pseudotsuga menziesii Franco), subalpine fir (Abies lasiocarpa Nutt.), and Engelmann spruce (Picea engelmannii Parry ex Engelm.). The study area also contains a sparse understory of shrubs and herbaceous vegetation. Average annual temperatures range from -5.7 to $10.7^{\circ} \mathrm{C}$; average annual precipitation is $93 \mathrm{~cm}$ (1971-2000; PRISM Data Explorer, http://prismmap.nacse. $\operatorname{org} / \mathrm{nn} /)$.

We stratified the study area using preoutbreak Landsat Thematic Mapper 5 imagery (Path 41, Row 29 acquired on September 20, 2002). Using the Environment for Visualizing Images (ENVI) software package, we performed atmospheric correction and applied the dark object subtraction method to convert digital numbers to top-of-canopy reflectance values (Chavez, 1996). We used the Normalized Difference Vegetation Index (NDVI) as an indicator of biomass because this index correlates with vegetation greenness and photosynthetic capacity and can be a good indicator of leaf area index or vegetation canopy cover (Jensen, 2007). Water and areas with solely herbaceous cover were masked with a minimum NDVI threshold of 0.39 , which we determined through visual inspection.

Field observations revealed that forest composition changed to more mixed forest containing lodgepole pine, subalpine fir, and Engelmann spruce at elevations above $2150 \mathrm{~m}$. To focus on areas where lodgepole pine dominates, we masked out elevations above $2150 \mathrm{~m}$ using a $10-\mathrm{m}$ digital elevation model (DEM). We also observed evidence of firewood cutting of beetle-killed trees, which is allowed within $91 \mathrm{~m}$ (300 ft) of major roads. We masked out areas within $91 \mathrm{~m}$ of major roads to minimize these impacts.

We divided the masked NDVI image into three equal areas of low, medium, and high strata; randomly placed candidate plot locations in each stratum; and selected 27 plots for measurement. The NDVI stratification was fragmented in many small areas, and many of the random plot locations were surrounded by strata other than what they were intended to represent. Although a qualitative check of the georegistration of our Landsat image in the field showed it to be georegistered to sub-pixel accuracy, to ensure that we sampled within the correct NDVI strata, we eliminated candidate plot locations that were surrounded or mostly surrounded by other strata. We used a Trimble GeoExplorer 2008 GPS receiver to navigate to the first nine acceptable target plots within each of the three NDVI strata.

\subsection{Field observations}

For each $11.3-\mathrm{m}$ radius plot $\left(400 \mathrm{~m}^{2}\right)$, we recorded coordinates of the plot center by logging 200 GPS locations, which we later differentially corrected using post processing. For each tree $>7 \mathrm{~cm}$ diameter at breast height ( $\mathrm{DBH}, 1.37 \mathrm{~m}$ ) within a plot, we recorded bearing and distance from plot center, species, health (live or dead), percent needles remaining, percent red needles, $\mathrm{DBH}$, height, height to bottom of crown, crown diameter, and canopy dominance. The presence of exit holes and pitch tubes were used to attribute the cause of death to beetle kill. Percent needles remaining and percent red needles were estimated through visual inspection in the field. Beetle-killed trees with at least $50 \%$ of original needles remaining were defined 


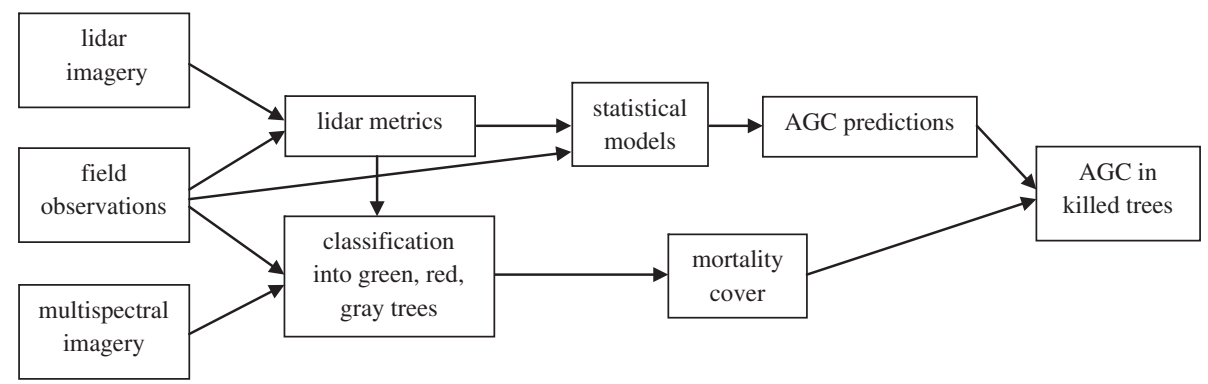

Fig. 1. Flow diagram describing the combination of field observations, lidar, and multispectral imagery to quantify aboveground carbon (AGC) in killed trees.

as red trees. Beetle-killed trees with less than $50 \%$ of original needles remaining were defined as gray trees. In addition to tree measurements, we collected 19 ground control points across the study area at features that would be recognizable on imagery for use in checking the coregistration between the multispectral imagery and our field observations.

\subsection{Aboveground carbon estimation using allometric equations}

We used allometric equations developed for lodgepole pine to calculate the AGC content of each tree. We applied allometric equations developed for lodgepole pine to all species because the vast majority of trees across the study area were lodgepole pine. We chose to use allometric equations developed by Standish et al. (1985) because they (1) include height as a predictor variable; (2) include separate stem, branch, and foliage equations; (3) were developed using a large sample size and range of DBH measurements; and (4) were developed in southern British Columbia, which was geographically closer to our study area than the locations of other studies we considered. Equations from Standish et al. (1985) are:

$$
\begin{aligned}
B_{\mathrm{s}}= & 3.2+9.1 \times \mathrm{DBH}^{2}+\mathrm{HT}+18.3+135.4 \times \mathrm{DBH}^{2} \times \mathrm{HT} \\
B_{\mathrm{b}}= & 0.8+3.2 \times \mathrm{DBH}^{2} \times \mathrm{HT}+5.8+7.4 \times \mathrm{DBH}^{2} \times \mathrm{HT}+1.2+1.7 \\
& \times \mathrm{DBH}^{2} \times \mathrm{HT}
\end{aligned}
$$

$B_{\mathrm{f}}=5.5+4 \times \mathrm{DBH}^{2} \times \mathrm{HT}$

where $B_{\mathrm{s}}$ is stem dry-weight biomass in $\mathrm{kg}, B_{\mathrm{b}}$ is branch dry-weight biomass in $\mathrm{kg}, B_{\mathrm{f}}$ is foliage dry-weight in biomass in $\mathrm{kg}$, DBH is diameter at breast height in $\mathrm{m}$, and HT is height in $\mathrm{m}$. For green (all species) and red trees, which had at least $50 \%$ of needles remaining by our field definition, we calculated total tree AGC by summing all three equations. For gray trees and other killed trees that did not have needles but still had branches, we summed Eqs. (1) and (2). For dead

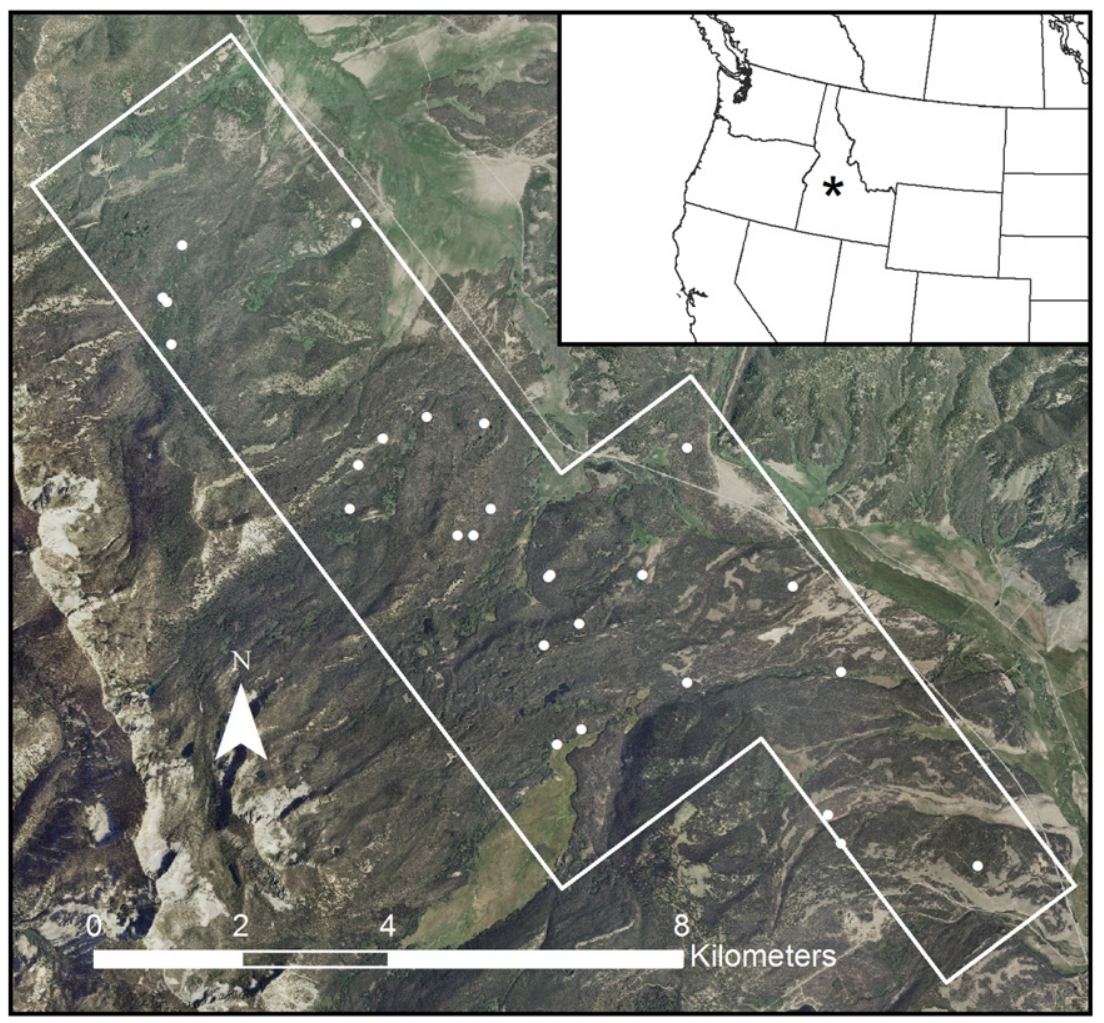

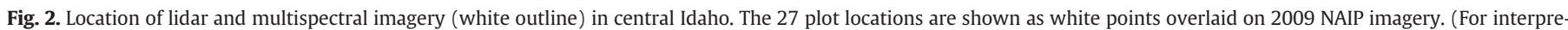
tation of the references to color in this figure legend, the reader is referred to the web version of this article.) 
trees that did not have branches, we only used Eq. (1) to calculate biomass. We then multiplied biomass of all trees by 0.5 to compute AGC for each tree (Lamlom \& Savidge, 2003). Plot AGC estimates were computed as the sum of all tree AGC estimates within a plot. We did not include trees $<7 \mathrm{~cm}$ in DBH or shrubs in our measurements of AGC. Hereafter we refer to AGC estimates derived from allometric equations as "observed" AGC values to distinguish them from AGC predictions derived from models, but it should be noted that these "observed" values are also estimates subject to error.

\subsection{Lidar specifications and processing}

While our field crew collected plot observations, Watershed Sciences (Corvallis, OR) gathered high-density, discrete-return lidar data of the study area using a Leica ALS50 Phase II sensor (Table 1). Watershed Sciences calculated laser point positions and filtered out point cloud outliers such as birds. Lidar data were separated into 142 tiles and delivered in LAS v.1.2 file format. The resulting lidar density averaged 8.7 returns per $\mathrm{m}^{2}$ across the study area.

Lidar intensity is the amount of energy reflected back to the lidar sensor. In forest canopies, intensity is a function of canopy properties, which include canopy reflectance, density, and foliage size and orientation, as well as sensor properties, which include lidar sensor-to-target range and automatic gain control (AGC) (Korpela et al., 2010a). Many researchers have successfully used raw lidar intensity data (not corrected for range and AGC) to characterize forests and distinguish between forest types (Garcia et al., 2010; Hudak et al., 2006; S. Kim et al., 2009; Y. Kim et al., 2009). However, other researchers have reported improved separation of vegetation types using range- and AGC-normalized lidar intensity, suggesting that intensity normalization removes unnecessary noise (Korpela, 2008; Korpela et al., 2009, 2010b). We normalized intensity values by range and AGC for each return using the BCAL LiDAR, 2011 Tools software package (http://bcal.geology.isu.edu/envitools. shtml) that uses the equation of Korpela et al. (2010a):

$I_{\text {norm }}-\mathrm{AGC}=\left(\frac{R}{R_{\text {ref }}}\right)^{a} \times I_{\text {raw }}+b \times I_{\text {raw }} \times(c-$ AGC $)$

where $I_{\text {norm }}$ is normalized intensity, AGC is automatic gain control, $R$ is sensor to target range, $R_{\mathrm{ref}}$ is the reference range or average flying height, $a=2, b=0.045$, and $c=127.5$ (default values of $a, b$, and $c$ given in Korpela et al. (2010a)).

To separate ground and non-ground returns, we used the Multiscale Curvature Classification (MCC) algorithm (Evans \& Hudak, 2007). We qualitatively assessed 15 different bare-earth digital terrain models (DTMs) of one lidar tile produced using different MCC parameters to classify ground returns, looking for bumps (errors of commission) and craters (errors of omission). The spacing parameter of 0.6667 and curvature threshold parameter of 0.07 minimized both errors of commission and errors of omission in the bare-earth DTM, so we used these parameters to separate ground and non-ground returns

Table 1

Lidar acquisition parameters.

\begin{tabular}{ll}
\hline Parameter & Specification \\
\hline Flying height & $900 \mathrm{~m}$ aboveground level \\
Flying speed & $194.5 \mathrm{~km} / \mathrm{hr}$ \\
Maximum scan angle from nadir & $\pm 13^{\circ}$ \\
Side-lap & $\geq 50 \%$ \\
Laser wavelength & $1064 \mathrm{~nm}$ \\
Laser beam divergence & $0.22 \mathrm{mrad}$ \\
Footprint diameter & $21 \mathrm{~cm}$ \\
Swath width & $416 \mathrm{~m}$ \\
Scan repetition frequency & $54 \mathrm{kHz}$ \\
Pulse repetition frequency & $83 \mathrm{kHz}$ \\
Pulse density & $8 \mathrm{pulses}$ per $\mathrm{m}^{2}$ \\
Returns per pulse & Up to 4 \\
\hline
\end{tabular}

for all lidar data. Using the FUSION software package (McGaughey, 2008), we then produced a bare-earth DTM where cells were assigned the mean elevation of coincident ground-classified returns. We subtracted the bare-earth DTM from non-ground-classified returns to calculate the height of each non-ground return. We defined vegetation returns as those $>0.5 \mathrm{~m}$ above the bare-earth DTM.

A comparison of the lidar-derived canopy height model (CHM), in which a $0.5-\mathrm{m}$ raster grid was assigned the highest return within each cell, and field-observed tree centers showed that lidar data and field observations were coregistered well. To quantify the difference between lidar data and field observations, we determined canopy maxima of the CHM using FUSION software (Popescu et al., 2002) and compared canopy maxima locations with field-observed tree locations. We found a root mean square error (RMSE) of $1.27 \mathrm{~m}$ between 283 canopy maxima and corresponding field-observed tree locations. To reduce registration differences between our field measurements and lidar data and therefore improve our statistical model, we calculated the average $x$ and $y$ bias for each plot and applied these to each plot center and therefore each tree location. Shifting tree locations reduced the RMSE for 283 trees from $1.27 \mathrm{~m}$ to $0.84 \mathrm{~m}$ (Figure $\mathrm{S} 1$ ).

We determined tree extents (crowns) by buffering CHM-corrected tree locations using canopy radius measurements. Plot extents were identified by buffering plot center points by $11.3 \mathrm{~m}$. Using FUSION software, we clipped lidar returns in each plot and tree extent and produced 97 lidar metrics for each extent. We identified highly correlated metric pairs $(r>0.9)$ and eliminated one metric from these pairs, resulting in 15 candidate metrics (Table 2). We also produced 2.4-m (the average crown width of canopy trees) lidar metric grids across plot extents for use in applying tree-level models to predict plot-level AGC.

\subsection{Multispectral imagery processing}

Watershed Sciences also acquired multispectral imagery of the study area using a Vexcel Ultra Cam D large-format mapping camera. Acquisition parameters included (1) blue, green, red, and near-infrared spectral bands, (2) 0.2-m pixel resolution, (3) 30\% sidelap, and (4) 16-bit pixel depth. Watershed Sciences orthorectified the multispectral imagery to the lidar intensity image and delivered the imagery in 142 GeoTiff tiles. The vendor found an RMSE of $0.36 \mathrm{~m}$ between 124 control points located on the aerial imagery and the lidar intensity image. We mosaicked these tiles and then scaled digital numbers to values between 0 and 1 by dividing by $65,535\left(2^{16}-1\right)$. Comparison of our 19 ground control points with the imagery also showed good agreement, so we did not perform further georectification.

In a classification of beetle-killed areas, Meddens et al. (2011) found that a pixel resolution of $2.4 \mathrm{~m}$, about the width of a tree crown, resulted in the highest classification accuracies of four resolutions ranging from 0.3 to $4.2 \mathrm{~m}$. Thus, we aggregated the original $0.2-\mathrm{m}$ imagery to a resolution of $2.4 \mathrm{~m}$, the approximate average crown width of canopy trees in our study area, by averaging $0.2 \mathrm{~m}$ pixel values. Using the $2.4-\mathrm{m}$ aggregated imagery, we masked NIR values below 0.15 to exclude water. To mask shadow and some additional water, we excluded pixels with a red value of less than 0.19. Threshold values that excluded water and shadow were determined using visual inspection. We masked herbaceous and non-forest cover $<0.5 \mathrm{~m}$ in height using the lidar-derived 2.4-m CHM, similar to the CHM described above. We produced Normalized Difference Vegetation Index (NDVI) and Red/Green Index (RGI) images of the 2.4-m imagery to be used as additional variables. Formulas for NDVI and RGI are:

$$
\begin{aligned}
& \text { NDVI }=\frac{\text { NIR }- \text { RED }}{\text { NIR }+ \text { RED }} \\
& \text { RGI }=\frac{\text { RED }}{\text { GREEN }}
\end{aligned}
$$

where NIR is the near-infrared band, RED is the red band, and GREEN is the green band. 
Table 2

Candidate explanatory variables.

\begin{tabular}{|c|c|}
\hline Metric name & Metric description \\
\hline UTM.E, UTM.N & UTM Easting, UTM Northing \\
\hline HMAX & Maximum height of vegetation returns ${ }^{a}$ \\
\hline HMEAN & Mean height of vegetation returns \\
\hline HSD & Standard deviation of height of vegetation returns \\
\hline HP25 & 25 th percentile of height of vegetation returns \\
\hline HP50 & 50th percentile of heights or median height of vegetation returns \\
\hline DEN & Density (vegetation returns / total returns $\times 100$ ) \\
\hline $\mathrm{D}<10$ & Percentage of vegetation returns $<10 \mathrm{~m}$ \\
\hline $\mathrm{D}>10$ & Percentage of vegetation returns $>10 \mathrm{~m}$ \\
\hline IMAX & Maximum intensity of vegetation returns \\
\hline IMEAN & Mean intensity of vegetation returns \\
\hline ISD & Standard deviation of intensities of vegetation returns \\
\hline IP50 & 50th percentile of intensities or median intensity of vegetation returns \\
\hline SLOPE & Slope ${ }^{b}$ \\
\hline TRASP & Topographic Solar Radiation Index Transformation of Aspect $\left(1-\operatorname{cosine}\right.$ aspect $\left.\left.{ }^{\mathrm{b}}-30\right)\right) / 2$ (Roberts \& Cooper, 1989) \\
\hline GREEN $^{\mathrm{c}}$ & Percent canopy green \\
\hline $\mathrm{RED}^{\mathrm{c}}$ & Percent canopy red \\
\hline GRAY ${ }^{\mathrm{c}}$ & Percent canopy gray \\
\hline
\end{tabular}

a Vegetation returns defined as returns $>0.5 \mathrm{~m}$ above the bare-earth digital terrain model.

b Degrees.

c Multispectral variables that were only included in the plot-level model analysis.

After masking water, shadow, and non-forest pixels, we used field observations along with the $0.2-\mathrm{m}$ unaggregated true-color imagery to guide our selection of 2.4-m class member pixels for each tree class. RGI separated red trees from green and gray trees well, so we used an RGI threshold of $>1.08$, which we determined through a spectral analysis of class member pixels, to classify red trees (Coops et al., 2006; Hicke \& Logan, 2009). We found that using an RGI threshold eliminated overestimation of red tree cover that occurred in a maximum likelihood classifier. To classify green and gray trees, we randomly selected two-thirds of green and gray class member pixels for training of a maximum likelihood classification that used NDVI, RGI, and NIR as variables (Fig. 3). The remaining one-third of the green and gray class member pixels and the entire group of red class member pixels were used for classification evaluation.

\subsection{Relating aboveground carbon to lidar metrics through statistical modeling}

\subsubsection{Tree-level models}

We developed three tree-level models that related AGC to lidar metrics, with one model for each tree class: green (including lodgepole pine and other coniferous species), red, and gray. A total of 1379 trees were measured in the field; We eliminated 590 trees that were not suitable for analysis based on field observations, including those with excessive tree lean (actual field-observed tree lean), snags without branches, understory trees, trees not killed by beetles, erroneously measured trees, and one large outlier (Douglas-fir with high AGC), leaving 515 (65\%) green, 32 (4\%) red, and 242 (31\%) gray tree AGC measurements, along with corresponding lidar metrics, for model development.

Distributions of tree AGC measurements were positively skewed. Preliminary linear regression models relating untransformed variables to lidar metrics produced heteroscedastic residuals, i.e., residual variance tended to increase with tree AGC. To normalize distributions of tree AGC measurements, we performed a natural-log transformation of the response variable, tree AGC. Residuals of preliminary linear models also tended to be positively spatially autocorrelated, suggesting that the basic assumption of independent observations and errors had been violated. Spatially autocorrelated residuals also suggested that geographic location accounted for some variation in tree AGC. This variation was likely a result of variability in study area conditions (e.g., edaphic factors) both within a plot and across plots that we were unable to capture with existing data sets. Additive modeling allows for the incorporation of bivariate spatial terms (Hobert et al., 1997; Wood \& Augustin, 2002). Additive models can also model nonlinear relationships between response and explanatory variables through fitting smoothing functions, rather than linear coefficients. For these reasons, we developed additive models relating tree AGC to lidar metrics using the gam() function in $R$ (R Development Core Team, 2011), part of the mgcv package (Wood, 2011). For each tree class we performed a best subsets model analysis for models having 1-5 predictor variables, where we built models relating natural

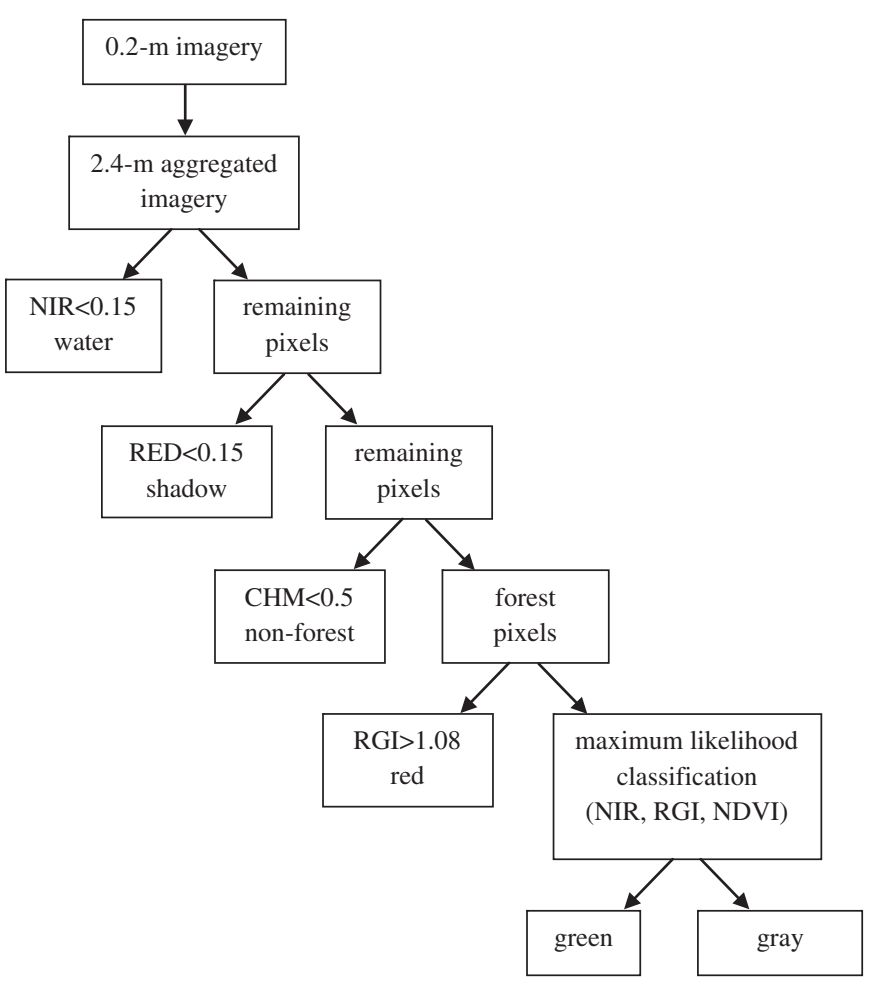

Fig. 3. Flow diagram describing multispectral imagery classification process. Abbreviations: 'NIR', near-infrared band; 'RED', red band; 'CHM', 2.4-m canopy height model derived from lidar data; 'RGI', Red/Green Index; 'NDVI', Normalized Difference Vegetation Index. 
log-transformed tree AGC to smoothing functions of every combination of 15 candidate variables (Table 2). We identified the five models that minimized the Akaike Information Criterion (AIC) for models with 1-5 predictor variables. For each tree class, we selected the model that minimized AIC and for which all smoothing functions were significantly different from zero (defined as when the $95 \%$ confidence intervals do not include zero).

\subsubsection{Plot-level models}

Plot AGC measurements were normally distributed and residuals of preliminary linear regression models were homoscedastic and not spatially autocorrelated, so we used linear regression to relate plot AGC to plot metrics. In addition to the 15 variables used in tree-level models, we also included green, red, and gray percentage variables, which we derived from the multispectral classification (Table 2). We used an exhaustive search in the regsubsets() function, part of the leaps package of $R$ (Lumley, 2009), to perform a best subsets regression analysis relating plot AGC to 18 candidate variables. For models with 1-18 predictor variables, the best subsets regression analysis identified the two models that minimized AIC. We selected the model that minimized AICc where all variables were significantly different from zero at the 95\% confidence level.

\subsection{Applying regression models to predict aboveground carbon}

To assess model performance in predicting new AGC values, we performed cross-validation by excluding one plot at a time from model development and using each excluded plot for evaluation. We then compared predicted AGC with observed AGC. For the plot-level model, this process was equivalent to leave-one-out-cross-validation. For treelevel models, the number of trees excluded for cross-validation varied.
We applied original models that included all plot information, not models produced for cross-validation, to predict plot AGC.

We applied tree-level models to 2.4-m lidar metric grids within plot extents to predict total AGC and AGC by tree class for each plot. Model output grids were back-transformed to original units and corrected for transformation bias by multiplying the backtransformed grid by the ratio estimator, which is the ratio of the arithmetic sample mean and the back-transformed model mean (Snowdon, 1991). Back-transformation correction factors for green, red, and gray models were 1.063, 1.033, and 1.051, respectively.

Plot-level models predicted total plot AGC. To separate total plot AGC into individual green, red, and gray AGC amounts, we multiplied predicted AGC plot totals by percent tree cover by class derived from the multispectral classification. We compared both tree and plot model predicted plot AGC with observed plot AGC.

\section{Results}

\subsection{Field observations}

We measured a total of 1379 trees in 27 plots. Of all these, 1222 (89\%) were lodgepole pine, of which 679 (56\%) were green, 52 (4\%) were recently attacked green, 46 (3\%) were red, 362 (30\%) were gray, and 83 (7\%) were dead trees not killed in the current outbreak. Plot density averaged 1277 trees/ha and ranged from 425 to 2175 trees/ha. In terms of number of trees, lodgepole pine mortality by plot averaged $38 \%$, ranging from $7 \%$ to $76 \%$. For all tree species, tree mortality by plot averaged $33 \%$. In terms of AGC, lodgepole pine mortality by plot averaged $48 \%$, ranging from $22 \%$ to $91 \%$. For all tree species, tree mortality by plot averaged $42 \%$, ranging from $13 \%$ to $85 \%$. All plots except two were dominated by lodgepole
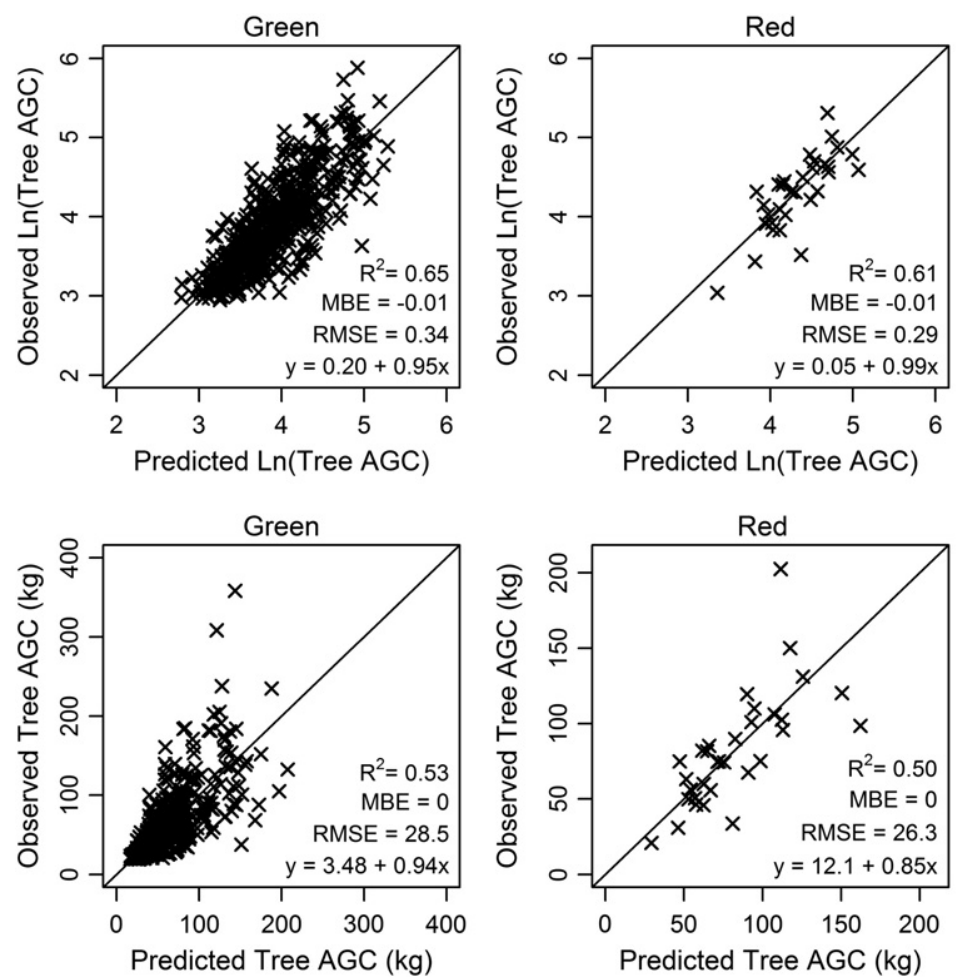
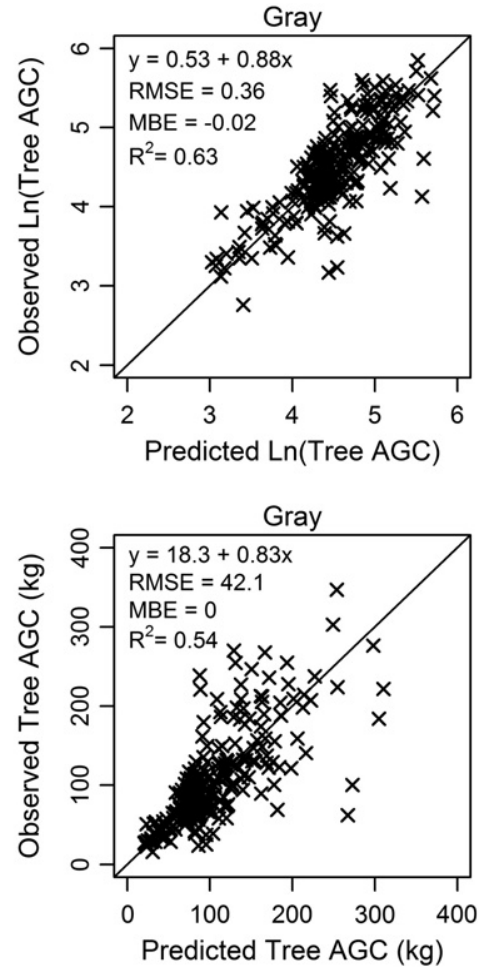

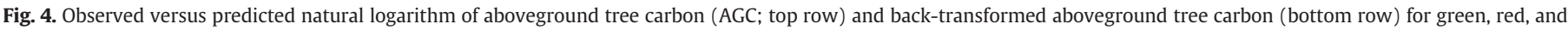

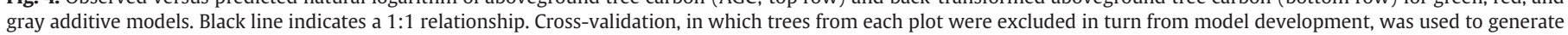
predicted values for model evaluation. 
Table 3

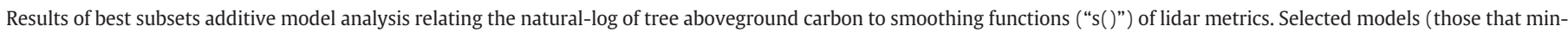

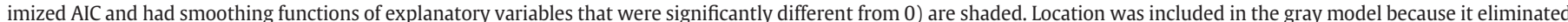

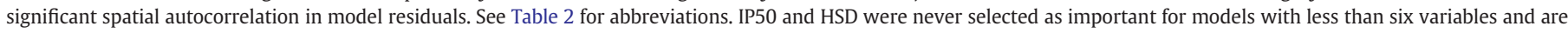
not shown on the table. No two variables with pairwise correlations of $r>0.9$ included in same model.

\begin{tabular}{|c|c|c|c|c|c|c|c|c|c|c|c|c|c|c|c|c|}
\hline \# Var. & Int. & UTM.E,UTM.N & HMAX & HMEAN & HP25 & HP50 & DEN & $\mathrm{D}<10$ & $\mathrm{D}>10$ & IMAX & IMEAN & ISD & SLOPE & TRASP & $R^{2}$ & $\mathrm{AIC}^{\mathrm{a}}$ \\
\hline \multicolumn{17}{|l|}{ Green } \\
\hline 1 & $* * *$ & & $* * *$ & & & & & & & & & & & & 0.63 & 387.4 \\
\hline 2 & $* * *$ & & $* * *$ & & & & & & & $* * *$ & & & & & 0.65 & 357.8 \\
\hline 3 & $* * *$ & $* * *$ & $* * *$ & & & & & & & $* * *$ & & & & & 0.69 & 316.5 \\
\hline 4 & $* * *$ & $* * *$ & $* * *$ & & & $* * *$ & & & & $* * *$ & & & & & 0.71 & 297.0 \\
\hline 5 & $* * *$ & $* * *$ & $* * *$ & & & $* * *$ & ns & & & $* * *$ & & & & & 0.72 & 293.7 \\
\hline \multicolumn{17}{|l|}{ Red } \\
\hline 1 & $* * *$ & & $* * *$ & & & & & & & & & & & & 0.67 & 13.04 \\
\hline 2 & $* * *$ & & $* * *$ & & & & & & ns & & & & & & 0.72 & 11.97 \\
\hline 3 & $* * *$ & & $* * *$ & & ns & & & ns & & & & & & & 0.74 & 13.40 \\
\hline 4 & $* * *$ & ns & $* * *$ & ns & & & & & & & & & & ns & 0.76 & 14.71 \\
\hline 5 & $* * *$ & & $* *$ & ns & & & & & & & ns & ns & ns & & 0.74 & 17.77 \\
\hline \multicolumn{17}{|l|}{ Gray } \\
\hline 1 & $* * *$ & & $* * *$ & & & & & & & & & & & & 0.65 & 179.6 \\
\hline 2 & $* * *$ & $*$ & $* * *$ & & & & & & & & & & & & 0.71 & 167.9 \\
\hline 3 & $* * *$ & & $* * *$ & & & & & & & $* * *$ & & $* * *$ & & & 0.70 & 157.6 \\
\hline 4 & $* * *$ & ns & $* * *$ & & & & & & & $* * *$ & & $* *$ & & & 0.72 & 153.6 \\
\hline 5 & $* * *$ & ns & $* * *$ & & & & & & & $* * *$ & & $* *$ & ns & & 0.75 & 146.8 \\
\hline
\end{tabular}

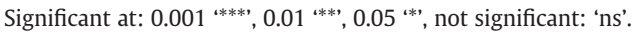

a AICc used in the red analysis because $n<40$.

pine. Plot AGC density averaged $77 \mathrm{Mg}$ AGC/ha and ranged from 27 to $121 \mathrm{Mg}$ AGC/ha (Tables S1, S2).

\subsection{Tree-level models}

Cross-validated green, red, and gray additive models explained 65, 61, and $63 \%$ of the variation in the natural log of tree AGC, with RMSE values of $0.34,0.29$, and $0.36 \ln (\mathrm{kg}$ AGC) (9, 7, and 8\%), respectively (Fig. 4). After back-transformation, variation in green, red, and gray tree AGC explained by models decreased to 53\%, 50\%, and 54\% with RMSE values of $28.5,26.3$, and $42.1 \mathrm{~kg}$ AGC (48\%, 32\%, and 39\%), respectively.

Maximum lidar height was the most frequently chosen explanatory variable in all three best subsets model analyses (Table 3). With the addition of an intercept term, this variable explained $63-67 \%$ of the variation a
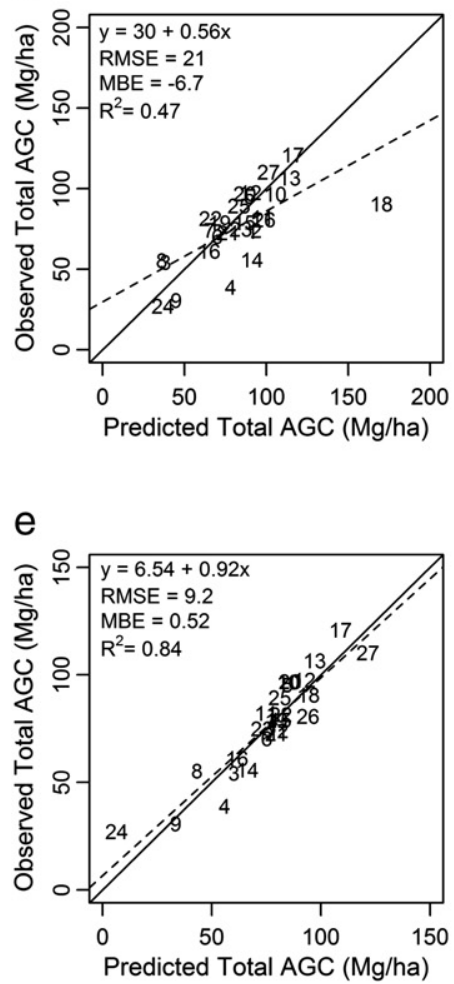

$b$

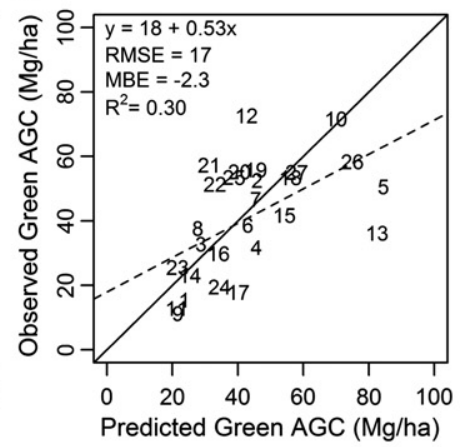

Tree-level models

$\mathrm{C}$

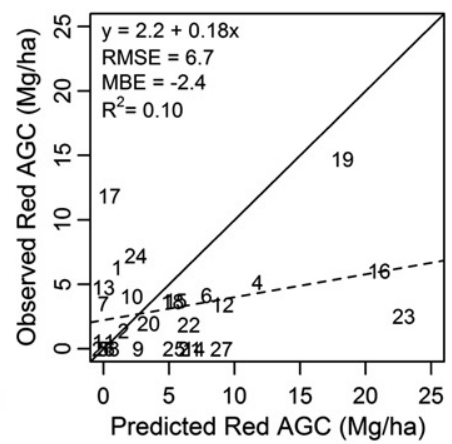

Plot-level model

$f$

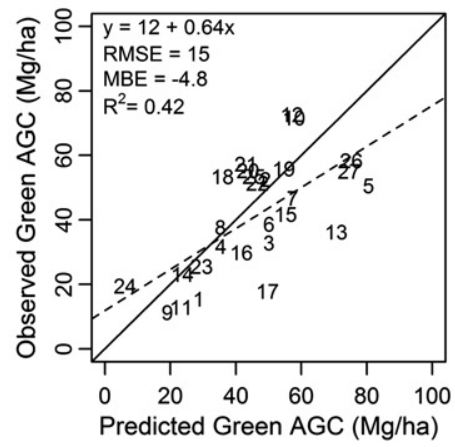

$\mathrm{g}$

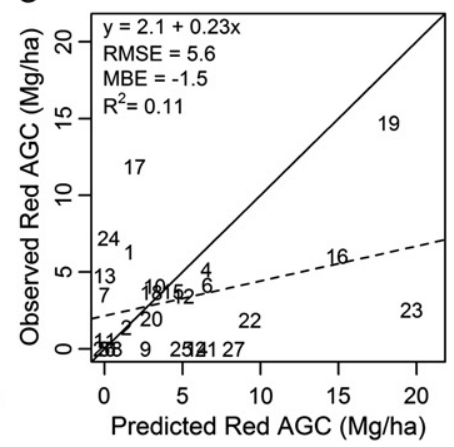

d

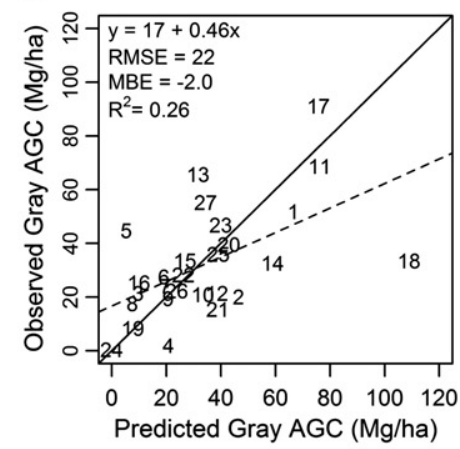

$\mathrm{h}$

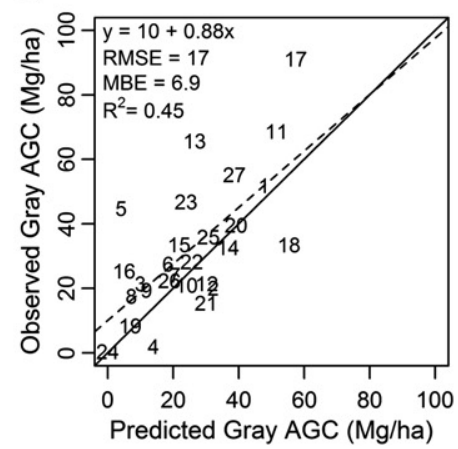

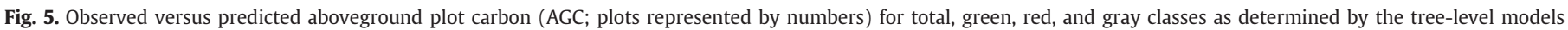

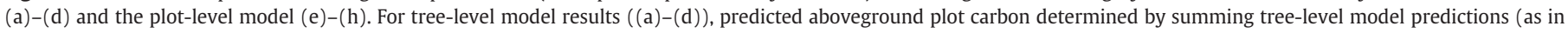

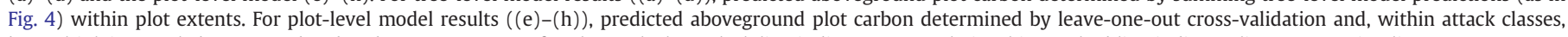
by multiplying total aboveground carbon by percent cover of each attack class. Black line indicates a 1:1 relationship. Dashed line indicates linear regression line. 
Table 4

Results of best subsets multiple linear regression analysis relating aboveground carbon to lidar metrics at the plot level. See Table 2 for meaning of abbreviations. Selected model is shaded. HMAX, HP50, D $<10$, D $>10$, IMEAN, ISD, IP50, GREEN, RED, and GRAY were never selected as important for models with less than six variables and are not shown on the table. No two variables with pairwise correlations of $r>0.9$ included in same model.

\begin{tabular}{|c|c|c|c|c|c|c|c|c|c|c|}
\hline \# Var. & Int. & HMEAN & HSD & HP25 & DEN & IMAX & SLOPE & TRASP & $R^{2}$ & AICC \\
\hline 1 & ns & & & & $* * *$ & & & & 0.64 & 50.0 \\
\hline 2 & $* * *$ & $* * *$ & & & $* * *$ & & & & 0.87 & 24.2 \\
\hline 3 & $* * *$ & $* * *$ & & & $* * *$ & & $*$ & & 0.90 & 20.5 \\
\hline 4 & $* * *$ & $* * *$ & & & $* * *$ & & $*$ & ns & 0.91 & 20.0 \\
\hline 5 & ns & & $* * *$ & $*$ & $* * *$ & $*$ & & ns & 0.92 & 19.3 \\
\hline
\end{tabular}

Significant at: $0.001^{\text {'***, }}, 0.01^{\text {'**’, }} 0.05^{\text {'*’, }}$, not significant: 'ns'.

in the response variable in all three one-variable tree-level models (not cross-validated). Tree location was also frequently chosen in the green and gray best subset model analyses and explained a large amount of the variation in the natural log of green tree AGC. Including tree location in the green and gray tree models eliminated spatial autocorrelation of residuals (Moran's I values not significantly different from zero). Residuals of the red tree model were not spatially autocorrelated so the inclusion of a spatial term was not necessary. Maximum lidar intensity improved the prediction of green and gray tree AGC and tended to increase with tree AGC. Median lidar height was frequently chosen in the green tree model analysis, and the standard deviation of lidar intensity was frequently chosen in the gray model analysis.

\subsection{Plot-level model}

A cross-validated, three-variable model using mean lidar height, canopy density (percent vegetation returns), and slope minimized AICc and explained $84 \%$ of the variation in plot AGC, with an RMSE of 9.2 Mg AGC/ha (12\%) (Fig. 5e; Table 4). Coefficients of all three variables in the above model were significantly different from zero at the 95\% level. Percent canopy cover of each tree class did not help to explain variation in plot AGC.

\subsection{Multispectral classification}

Classification of the 2.4-m aggregated multispectral imagery resulted in an accuracy of $87.2 \%$ and kappa value of 0.79 (Table 5). Both commission and omission errors were 3-24\% across classes. Visual inspection of classification images with true color imagery and field observations showed that red and gray cover were well predicted by the classification.

\subsection{Evaluation of tree-level and plot-level models}

\subsubsection{Total aboveground carbon}

We compared AGC measured in the field plots with plot AGC predicted by tree models and plot AGC predicted by the plot model
(Fig. 5). The plot model explained a greater amount of the variation in overall plot AGC $\left(R^{2}=0.84\right.$; Fig. 5e) compared with the tree model $\left(R^{2}=0.47\right.$; Fig. $\left.5 \mathrm{a}\right)$. The bias of the plot model (mean bias error (MBE) $=0.52 \mathrm{Mg} \mathrm{AGC} / \mathrm{ha}$ ) was smaller than the bias of the tree model, which tended to overestimate overall plot AGC ( $\mathrm{MBE}=-6.7 \mathrm{Mg} \mathrm{AGC} / \mathrm{ha})$. Plots 4, 14, and 18 were substantially overestimated (Fig. 5a). Examination of the tree model AGC predictions and field observations showed that 2.4-m pixels did not represent individual trees in two different ways: (1) Either two tree stems were very near to one another, so that both were contained in one 2.4-m grid cell (resulting in the map underestimating the number of trees compared with the field observations), or (2) one tree crown spanned more than one 2.4-m grid cell, causing that tree to be "counted" twice (resulting in overestimation in the map). These two types of misrepresentation offset one another in the majority of plots, as the majority of plots are well predicted, and the number of 2.4-m pixels in the AGC map approximates the number of fieldobserved trees (Figure S2). However, in the case of Plots 4, 14, and 18, several large tree crowns spanned more than one grid cell and were counted as more than one tree, causing overestimation of AGC within these plots. In Plot 18, severe overestimation of gray cover by the multispectral classification also caused plot AGC to be overestimated.

\subsubsection{Aboveground carbon in killed trees}

AGC by tree class was predicted less accurately than overall plot AGC by both models (Fig. 5). Tree-level models explained 30\%, 10\%, and $26 \%$ of the variation in plot sums of green, red, and gray AGC, respectively. Plot-level models explained $42 \%, 11 \%$, and $45 \%$ of the variation in plot sums of green, red, and gray AGC, respectively.

We identified three reasons for inaccuracy: First, although the multispectral classification was highly accurate (87\%), trees were occasionally misclassified, causing inaccuracy when both tree- and plot-level AGC predictions were combined (Table 5). In Plots 5 and 13, gray trees were occasionally classified as green, most likely because of confusion with understory vegetation, causing green AGC to be overestimated and gray AGC to be underestimated (Figs. 5b, f, d, h). In Plots 16 and 23 , several gray trees that still held red needles were classified as red trees, causing overestimation of red AGC (Figs. 5c, g). Red trees were occasionally classified as both green and gray trees as well, leading to underestimation of red AGC in several plots.

Second, apparent "tree lean" of off-nadir imagery, which occurs when tree tops are displaced from tree bases so that trees appear to "lean" over, caused misregistration between the aerial imagery and lidar data (Fig. 6). Apparent tree lean especially caused inaccuracy when combining tree-level AGC predictions with the tree-level classification because tree displacement of only a few meters could cause a 2.4-m AGC pixel to be overlaid with an incorrect classification. In Plots 12, 18, and 21, apparent gray tree lean into plot extents and shadow cover caused gray AGC to be overestimated and green AGC to be underestimated (Figs. 5b, f, d, h). In Plot 17, apparent green tree lean into the plot extent caused green AGC to be overestimated and gray AGC to be underestimated (Figs. 5b, f, d, h).

Table 5

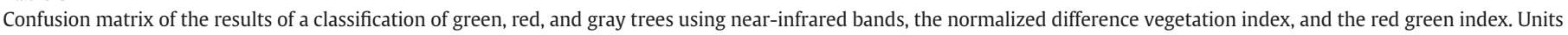
are 2.4-m pixels.

\begin{tabular}{|c|c|c|c|c|c|c|c|}
\hline & \multicolumn{7}{|c|}{ Ground reference } \\
\hline & Class & Green & Red & Gray & Total & User acc. & Comm. error \\
\hline \multirow[t]{6}{*}{ Classification } & Green & 157 (90.8\%) & $10(13.0 \%)$ & $8(10.1 \%)$ & 175 & $89.7 \%$ & $10.3 \%$ \\
\hline & Red & $0(0 \%)$ & $61(79.2 \%)$ & $2(2.5 \%)$ & 63 & $96.8 \%$ & $3.2 \%$ \\
\hline & Gray & $16(9.2 \%)$ & $6(7.8 \%)$ & $69(87.4 \%)$ & 91 & $75.8 \%$ & $24.2 \%$ \\
\hline & Total & 173 & 77 & 79 & \multicolumn{3}{|l|}{329} \\
\hline & Prod. acc. & $90.8 \%$ & $79.2 \%$ & $87.3 \%$ & \multicolumn{3}{|c|}{ Overall accuracy $=87.2 \%$} \\
\hline & Omis. error & $9.3 \%$ & $20.8 \%$ & $12.7 \%$ & \multicolumn{3}{|c|}{ Карра $=0.790$} \\
\hline
\end{tabular}


Plot 18

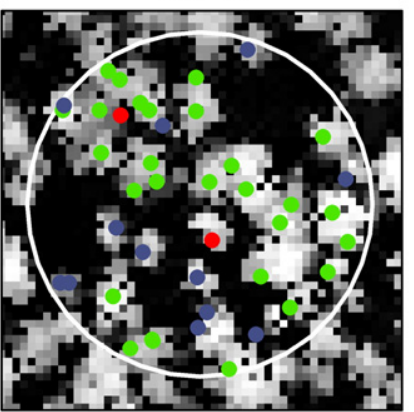

Plot 18

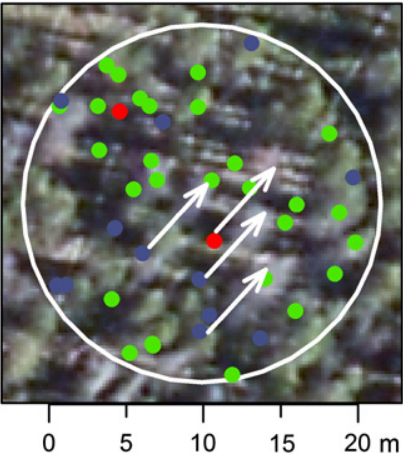

Plot 23

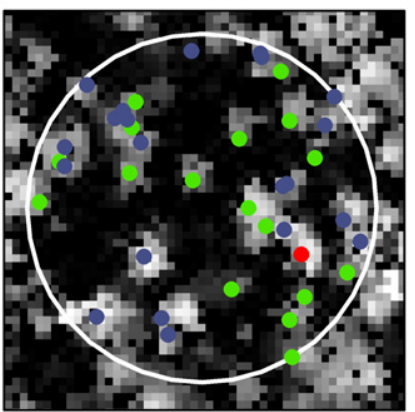

Plot 23

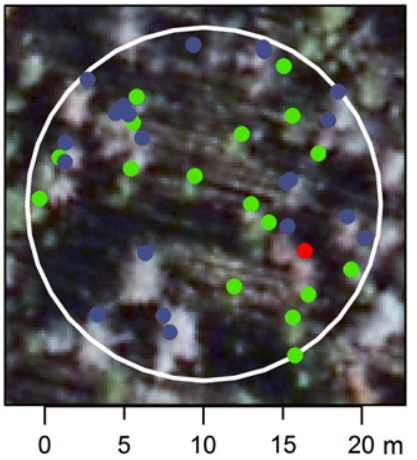

Canopy height $(\mathrm{m})$

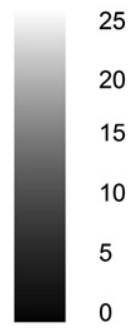

Field-observed trees

- Green

- Red

- Gray

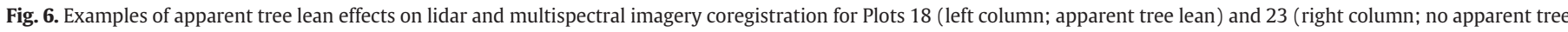

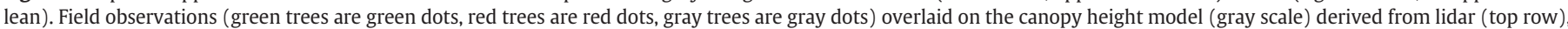

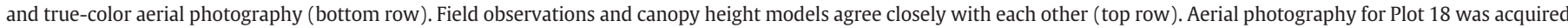

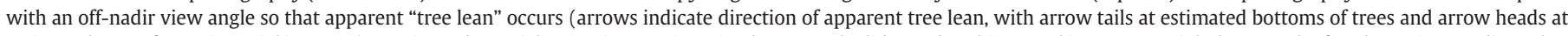

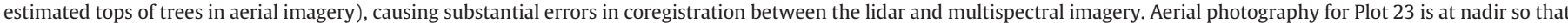
apparent tree lean is minimal. (For interpretation of the references to color in this figure legend, the reader is referred to the web version of this article.)

Third, percent cover (used to separate plot-level AGC predictions by tree class) was a biased approximation of percent AGC (Fig. 7). This caused systematic overestimation of green plot AGC $(\mathrm{MBE}=$ $-4.8 \mathrm{Mg} \mathrm{AGC} / \mathrm{ha}$ ) and systematic underestimation of gray AGC $(\mathrm{MBE}=6.9 \mathrm{Mg} \mathrm{AGC} / \mathrm{ha})$ (Figs. 5f, 5h). The tree-level approach was not affected by this bias; each tree class was overestimated similarly $(\mathrm{MBE}=-2.3$ and $-2.0 \mathrm{Mg}$ AGC/ha) (Figs. 5b, d). In the case of red trees, the MBE of the relationship between percent canopy area and percent AGC was much lower, leading to an lower MBE of observed versus predicted AGC with the plot-level model ( $-1.5 \mathrm{Mg}$ AGC/ha) compared with the tree-level model ( $-2.4 \mathrm{Mg}$ AGC/ha).

\section{Discussion}

\subsection{Statistical modeling of aboveground carbon}

We developed both plot-level and tree-level models relating AGC to lidar metrics. We found similarities between tree- and plot-level models. First, tree-level and plot-level models both explained a large amount of the variation in $\ln ($ AGC) and plot AGC, respectively. Second, natural log-transformed tree AGC and plot AGC were related approximately linearly to lidar metrics. Other studies have related natural log-transformed biomass to lidar metrics using linear models

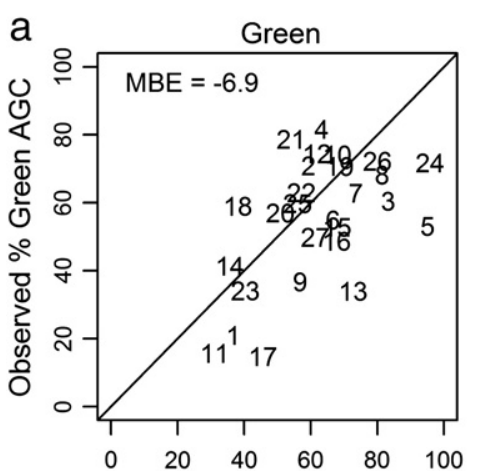

Predicted \% Green Canopy Area

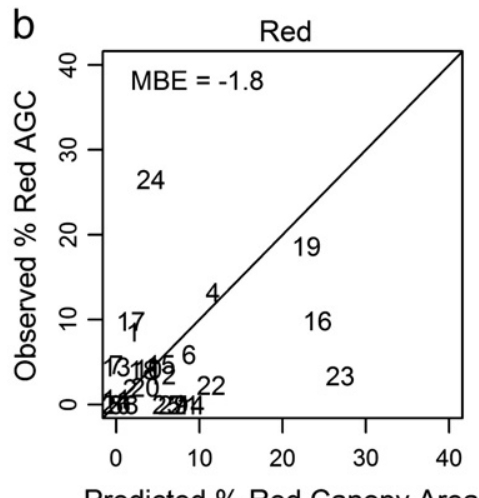

Predicted \% Red Canopy Area

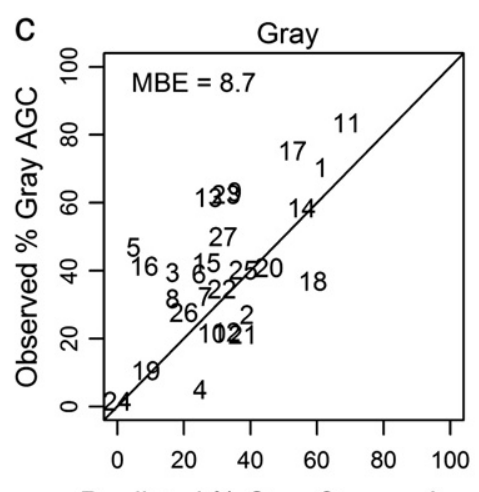

Predicted \% Gray Canopy Area

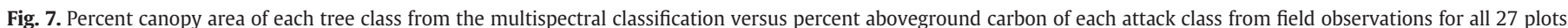

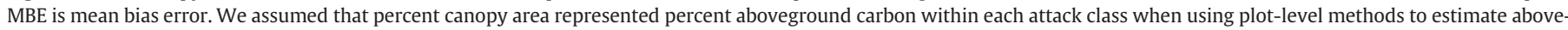

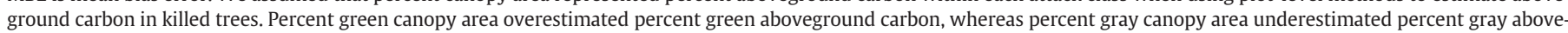

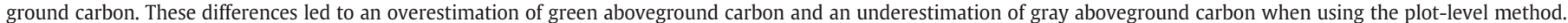


(Garcia et al., 2010; Hudak et al., 2006; Nelson et al., 1988), but none used additive modeling to demonstrate that a linear relationship exists. Nonlinear exceptions included median lidar height, which was related to $\ln (\mathrm{AGC})$ curvilinearly in the green tree model, and the standard deviation of lidar intensity, which tended to decrease with $\ln$ (AGC) and was lower in trees of large AGC content in the gray model (Figure S3). Third, mean or median lidar height, density metrics, and maximum lidar intensity were chosen in best subset model analyses for both types of models.

We also found differences in tree- and plot-level models. Maximum height was the more important predictor variable in tree-level models, whereas mean height was the more important predictor variable in plot-level models. Canopy density (percent vegetation returns) was consistently chosen in the plot-level best subsets analysis and explained a large amount of the variation in plot AGC, but was not as important in tree-level models. Location was not needed in the plot-level models but was important in tree-level models. In addition to minimizing spatial autocorrelation of residuals, location helped explain additional variation across plots in green and gray tree AGC, possibly because location acted as a proxy for variables that we did not measure such as soil fertility and composition.

Lidar metrics included in our models have been used in other studies relating biomass to lidar metrics. At the tree level, Popescu (2007) and Heurich (2008) also used maximum lidar height to estimate individual tree biomass. Salas et al. (2010) also found that including tree location improved statistical models relating tree diameter to lidar metrics. At the plot level, we further confirmed the ability of canopy cover and lidar height metrics such as mean height to effectively predict biomass, a fact that has been demonstrated by others (Lefsky et al., 2002; Means et al., 1999; Naesset \& Gobakken, 2008). Maximum intensity increased with AGC in green and gray models, and the standard deviation of intensity decreased with AGC in the gray model. Intensity metrics were likely responding to differences in branch and foliage biomass (Garcia et al., 2010).

\subsection{Causes of uncertainty when combining lidar and multispectral imagery}

We identified several causes of inaccuracy introduced by combining lidar and multispectral imagery. Misclassification of aerial imagery caused inaccuracy in estimates of the amount of AGC in killed trees. Our assumption that one 2.4-m pixel represented one tree, although guided by our crown area measurements, sometimes led to overestimates of plot-level AGC by the tree-level models. Overlapping trees tended to compensate for this effect in the majority of our plots. An object-oriented approach might have allowed us to account for variable crown sizes. Future studies should consider object-oriented techniques to minimize these effects. We used a pixel-based approach because of its relative simplicity and the difficulty of segmenting individual tree crowns in both lidar data and multispectral imagery in a closed-canopy forest. Some plots contained very large Douglas-fir trees, whose AGC content was overestimated because of double-counting. Douglas-fir trees were usually classified as green, so the presence of these trees tended to decrease the predicted proportion of AGC contained in beetle-killed trees.

We found that apparent tree lean caused by off-nadir aerial imagery resulted in coregistration differences between the multispectral imagery and lidar data that led to errors when using both products. Apparent tree lean should be taken into consideration in future studies that combine multispectral imagery and lidar data in forested areas. Valbuena et al. (2011) also found that apparent tree lean caused reduced accuracy when combining multispectral imagery and lidar data. Apparent tree lean affected the combination of 2.4-m AGC grids with the multispectral classification more because tree displacement often caused 2.4-m AGC pixels to be assigned to incorrect tree classes. Using high-resolution satellite imagery, which can have smaller view zenith angles over larger areas so that apparent tree lean is reduced, rather than aerial photography is one possible solution to reducing combination issues between multispectral imagery and lidar data.

Percent cover, which we used to separate plot-level AGC predictions by tree class, was a biased approximation of percent AGC because beetle-killed trees were larger and therefore contained significantly more AGC, on average, than live trees. Beetles prefer to attack larger trees (Figure S4) (Hopping \& Beall, 1948; Pfeifer et al., 2011). Separating AGC by tree class based on percent cover wrongly assumes that AGC densities of live and beetle-killed trees are identical, leading to overestimation of green AGC and underestimation of gray AGC.

Lastly, we did not measure or quantify trees $<7 \mathrm{~cm}$ in DBH and other understory vegetation with field observations. Although understory vegetation represents only a small proportion of AGC in our study area, this vegetation will respond positively to decreased competition for light, nutrients, and water, thereby offsetting live AGC stock reductions caused by bark beetle mortality. Also, the development of our tree-level models did not include understory trees that were overtopped by canopy-dominant trees. Inclusion of these smaller trees in our tree-level models would tend to decrease tree-level model AGC predictions and decrease the explanatory power of tree-level models.

Our study area was particularly well suited for developing a pixelbased, tree-level AGC model, as it was dominated by lodgepole pine with very similar tree crown diameters. The presence of other conifer species, which we assumed to be green lodgepole pine trees, caused some additional uncertainty in green AGC estimates. This assumption was reasonable in our study area, where lodgepole pine was the dominant tree species, but updated methods should be considered in forests with more mixed species composition. Also, other forests with more variable tree crown diameters might not be as well suited for predicting AGC using the pixel-based, tree-level approach presented here.

\section{Conclusions}

We found that tree-level models relating AGC to lidar metrics are comparable with plot-level models, although our tree-level models explained less variation in AGC and estimates were less certain (large \%RMSE values). Overlapping and double-counting of trees when treelevel models were applied reduced the accuracy of AGC estimates. As a result, plot-level AGC models predicted overall AGC more accurately. We suggest that plot-level models are sufficiently accurate for estimating AGC when AGC estimates at the tree resolution are unnecessary. By combining a multispectral classification of tree mortality with our AGC predictions, we were able to separate AGC by tree class, although separation accuracy suffered from multispectral classification errors, apparent tree lean in aerial imagery, and bias error between percent AGC and percent canopy area. Apparent tree lean issues could be addressed using satellite imagery or geometric modeling of tree canopies. Bias error between percent AGC and percent canopy area was not present when separate tree-level models were used to predict AGC by tree class, thus tree-level models are valuable in some circumstances. Our study confirms the utility of combining lidar and multispectral remote sensing for estimating impacts of bark beetle outbreaks found by Bater et al. (2010). Such capability will be critical for assessing landscape-scale effects of bark beetle outbreaks on forest ecosystems. In particular, documenting carbon shifts from live to beetle-killed trees increases understanding of the magnitude of carbon fluxes associated with reduced photosynthesis and increased decomposition, and therefore carbon sequestration. Furthermore, such spatial information is of great value as driver data sets for modeling studies of biogeochemical cycling.

\section{Acknowledgements}

This research was supported by the NSF Idaho EPSCoR Program and by the National Science Foundation under award number EPS-0814387, as well as by the USDA Forest Service Western Wildland Environmental Threat Assessment Center. We thank Lee Vierling, Troy Hall, Haiganoush 
Preisler, Arjan Meddens, Bonnie Ruefenacht, and Michael Falkowski for helpful suggestions and guidance. We are grateful for the help of Katrina Armstrong, Eric Creeden, and Steve Edburg in gathering field observations. We appreciate the assistance of Linda Tedrow and Rupesh Shrestha with lidar processing, and the prompt and insightful comments of two anonymous reviewers.

\section{Appendix A. Supplementary data}

Supplementary data to this article can be found online at http:// dx.doi.org/10.1016/j.rse.2012.05.016.

\section{References}

Amman, G., McGregor, M., \& Dolph, R., Jr. (1990). Forest insect and disease leaflet 2: Mountain pine beetle. Washington D.C.: USDA Forest Service.

Bater, C. W., Wulder, M. A., White, J. C., \& Coops, N. C. (2010). Integration of LIDAR and digital aerial imagery for detailed estimates of lodgepole pine (Pinus contorta) volume killed by mountain pine beetle (Dendroctonus ponderosae). Journal of Forestry, 108, 111-119.

BCAL LiDAR Tools ver 2.X.X. Boise, Idaho: Idaho State University, Department of Geosciences, Boise Center Aerospace Laboratory (BCAL). URL: http://bcal.geology. isu.edu/envitools.shtml accessed in June 2011.

Brown, M., Black, T. A., Nesic, Z., Foord, V. N., Spittlehouse, D. L., Fredeen, A. L., Grant, N. J., Burton, P. J., \& Trofymow, J. A. (2010). Impact of mountain pine beetle on the net ecosystem production of lodgepole pine stands in British Columbia. Agricultural and Forest Meteorology, 150, 254-264.

Chavez, P. S. (1996). Image-based atmospheric corrections revisited and improved. Photogrammetric Engineering and Remote Sensing, 62, 1025-1036.

Coops, N. C., Johnson, M., Wulder, M. A., \& White, J. C. (2006). Assessment of QuickBird high spatial resolution imagery to detect red attack damage due to mountain pine beetle infestation. Remote Sensing of Environment, 103, 67-80.

Dennison, P. E., Brunelle, A. R., \& Carter, V. A. (2010). Assessing canopy mortality during a mountain pine beetle outbreak using GeoEye-1 high spatial resolution satellite data. Remote Sensing of Environment, 114, 2431-2435.

Edburg, S. L., Hicke, J. A., Lawrence, D. M., \& Thornton, P. E. (2011). Simulating coupled carbon and nitrogen dynamics following mountain pine beetle outbreaks in the western United States. Journal of Geophysical Research-Biogeosciences, 116.

Evans, J. S., \& Hudak, A. T. (2007). A multiscale curvature algorithm for classifying discrete return LiDAR in forested environments. Ieee Transactions on Geoscience and Remote Sensing, 45, 1029-1038.

Franklin, S. E., Wulder, M. A., Skakun, R. S., \& Carroll, A. L. (2003). Mountain pine beetle red-attack forest damage classification using stratified Landsat TM data in British Columbia, Canada. Photogrammetric Engineering and Remote Sensing, 69, 283-288.

Garcia, M., Riano, D., Chuvieco, E., \& Danson, F. M. (2010). Estimating biomass carbon stocks for a Mediterranean forest in central Spain using LiDAR height and intensity data. Remote Sensing of Environment, 114, 816-830.

Hall, S. A., Burke, I. C., Box, D. O., Kaufmann, M. R., \& Stoker, J. M. (2005). Estimating stand structure using discrete-return lidar: an example from low density, fire prone ponderosa pine forests. Forest Ecology and Management, 208, 189-209.

Heurich, M. (2008). Automatic recognition and measurement of single trees based on data from airborne laser scanning over the richly structured natural forests of the Bavarian Forest National Park. Forest Ecology and Management, 255, 2416-2433.

Hicke, J. A., Allen, C. D., Desai, A. R., Dietze, M. C., Hall, R. J., Hogg, E. H., Kashian, D. M., Moore, D., Raffa, K. F., Sturrock, R. N., \& Vogelmann, J. (2012). Effects of biotic disturbances on forest carbon cycling in the United States and Canada. Global Change Biology, 18, 7-34.

Hicke, J. A., \& Logan, J. (2009). Mapping whitebark pine mortality caused by a mountain pine beetle outbreak with high spatial resolution satellite imagery. International Journal of Remote Sensing, 30, 4427-4441.

Hobert, J. P., Altman, N. S., \& Schofield, C. L. (1997). Analyses of fish species richness with spatial covariate. Journal of the American Statistical Association, 92, 846-854.

Hopkins, A. D. (1970). Practical information on the Scolytid beetles of North American forests, Part 1 bark beetles of the genus Dendroctonus. U.S. Government Research and Development Reports, 70, 47.

Hopping, G. R., \& Beall, G. (1948). The relation of diameter of lodgepole pine to incidence of attack by the bark beetle Dendroctonus monticolae Hopkins. Forestry Chronicle, 24, 141-145.

Hudak, A. T., Crookston, N. L., Evans, J. S., Falkowski, M. J., Smith, A. M. S., Gessler, P. E., \& Morgan, P. (2006). Regression modeling and mapping of coniferous forest basal area and tree density from discrete-return lidar and multispectral satellite data. Canadian Journal of Remote Sensing, 32, 126-138.

Hyyppa, J., Kelle, O., Lehikoinen, M., \& Inkinen, M. (2001). A segmentation-based method to retrieve stem volume estimates from 3-D tree height models produced by laser scanners. Ieee Transactions on Geoscience and Remote Sensing, 39, 969-975.

Jensen, J. R. (2007). Remote sensing of the environment, an earth resource perspective (2nd ed.). Upper Saddle River, NJ: Pearson Prentice Hall (Chapter 11).

Kim, S., McGaughey, R. J., Andersen, H. -E., \& Schreuder, G. (2009). Tree species differentiation using intensity data derived from leaf-on and leaf-off airborne laser scanner data. Remote Sensing of Environment, 113, 1575-1586.

Kim, Y., Yang, Z., Cohen, W. B., Pflugmacher, D., Lauver, C. L., \& Vankat, J. L. (2009). Distinguishing between live and dead standing tree biomass on the North Rim of
Grand Canyon National Park, USA using small-footprint lidar data. Remote Sensing of Environment, 113, 2499-2510.

Korpela, I. S. (2008). Mapping of understory lichens with airborne discrete-return LiDAR data. Remote Sensing of Environment, 112, 3891-3897.

Korpela, I., Koskinen, M., Vasander, H., Holopainen, M., \& Minkkinen, K. (2009). Airborne small-footprint discrete-return LiDAR data in the assessment of borea mire surface patterns, vegetation, and habitats. Forest Ecology and Management, 258, 1549-1566.

Korpela, I., Orka, H. O., Hyyppa, J., Heikkinen, V., \& Tokola, T. (2010a). Range and AGC normalization in airborne discrete-return LiDAR intensity data for forest canopies. Isprs Journal of Photogrammetry and Remote Sensing, 65, 369-379.

Korpela, I., Orka, H. O., Maltamo, M., Tokola, T., \& Hyyppa, J. (2010b). Tree species classification using airborne lidar-effects of stand and tree parameters, downsizing of training set, intensity normalization, and sensor type. Silva Fennica, 44, 319-339.

Kurz, W. A., \& Apps, M. J. (1999). A 70-year retrospective analysis of carbon fluxes in the Canadian forest sector. Ecological Applications, 9, 526-547.

Kurz, W. A., Dymond, C. C., Stinson, G., Rampley, G. J., Neilson, E. T., Carroll, A. L., Ebata, T., \& Safranyik, L. (2008). Mountain pine beetle and forest carbon feedback to climate change. Nature, 452, 987-990.

Lamlom, S. H., \& Savidge, R. A. (2003). A reassessment of carbon content in wood: variation within and between 41 North American species. Biomass E Bioenergy, 25, 381-388.

Lefsky, M. A., Cohen, W. B., Harding, D. J., Parker, G. G., Acker, S. A., \& Gower, S. T. (2002). Lidar remote sensing of above-ground biomass in three biomes. Global Ecology and Biogeography, 11, 393-399.

Lumley, T. (2009). Thomas using Fortran code by Alan Miller leaps: regression subset selection. R package version 2.9 (http://CRAN.R-project.org/package=leaps accessed in May 2011)

McGaughey, R. J. (2008). FUSION/LDV: software for LiDAR data analysis and visualization. USDA Forest Service, Pacific Northwest Research Station.

Means, J. E., Acker, S. A., Harding, D. J., Blair, J. B., Lefsky, M. A., Cohen, W. B., Harmon, M. E., \& McKee, W. A. (1999). Use of large-footprint scanning airborne lidar to estimate forest stand characteristics in the Western Cascades of Oregon. Remote Sensing of Environment, 67, 298-308.

Meddens, A. J. H., Hicke, J. A., \& Vierling, L. A. (2011). Evaluating the potential of multispectra imagery to map multiple stages of tree mortality. Remote Sensing of Environment, 115 1632-1642.

Mitchell, R. G., \& Preisler, H. K. (1998). Fall rate of lodgepole pine killed by the mountain pine beetle in central Oregon. Western Journal of Applied Forestry, 13, 23-26.

Naesset, E., \& Gobakken, T. (2008). Estimation of above- and below-ground biomass across regions of the boreal forest zone using airborne laser. Remote Sensing of Environment, 112, 3079-3090.

Nelson, R., Krabill, W., \& Tonelli, J. (1988). Estimating forest biomass and volume using airborne laser data. Remote Sensing of Environment, 24, 247-267.

Persson, A., Holmgren, J., \& Soderman, U. (2002). Detecting and measuring individual trees using an airborne laser scanner. Photogrammetric Engineering and Remote Sensing, 68, 925-932.

Pfeifer, E. M., Hicke, J. A., \& Meddens, A. J. H. (2011). Observations and modeling of aboveground tree carbon stocks and fluxes following a bark beetle outbreak in the western United States. Global Change Biology, 17, 339-350.

Popescu, S. C. (2007). Estimating biomass of individual pine trees using airborne lidar. Biomass E' Bioenergy, 31, 646-655.

Popescu, S. C., Wynne, R. H., \& Nelson, R. F. (2002). Estimating plot-level tree heights with lidar: local filtering with a canopy-height based variable window size. Computers and Electronics in Agriculture, 37, 71-95.

Popescu, S. C., Wynne, R. H., \& Scrivani, J. A. (2004). Fusion of small-footprint lidar and multispectral data to estimate plot-level volume and biomass in deciduous and pine forests in Virginia, USA. Forest Science, 50, 551-565.

R Development Core Team (2011). R: A language and environment for statistical computing. Vienna, Austria: R Foundation for Statistical Computing3-900051-07-0 (http://www. R-project.org/ accessed in July 2011)

Roberts, D. W., \& Cooper, S. V. (1989). Concepts and techniques of vegetation mapping. Land classifications based on vegetation-applications for resource management (pp. 90-96). Ogden, UT: USDA Forest Service GTR INT-257.

Romme, W. H., Knight, D. H., \& Yavitt, J. B. (1986). Mountain pine beetle outbreaks in the Rocky Mountains: Regulators of primary productivity. American Naturalist, 127, 484-494.

Salas, C., Ene, L., Gregoire, T. G., Naesset, E., \& Gobakken, T. (2010). Modelling tree diameter from airborne laser scanning derived variables: A comparison of spatial statistical models. Remote Sensing of Environment, 114, 1277-1285.

Snowdon, P. (1991). A ratio estimator for bias correction in logarithmic regressions. Canadian Journal of Forest Research-Revue Canadienne De Recherche Forestiere, 21, 720-724.

Standish, J. T., Manning, G. H., \& Demaerschalk, J. P. (1985). Development of biomass equations for British Columbia tree species. Information report BC-X-264. Vancouver BC: Pacific Forestry Centre, Canadian Forestry Service (47 pp.).

Stinson, G., Kurz, W. A., Smyth, C. E., Neilson, E. T., Dymond, C. C., Metsaranta, J. M., Boisvenue, C., Rampley, G. J., Li, Q., White, T. M., \& Blain, D. (2011). An inventorybased analysis of Canada's managed forest carbon dynamics, 1990 to 2008. Global Change Biology, 17, 2227-2244.

Stone, W. E., \& Wolfe, M. L. (1996). Response of understory vegetation to variable tree mortality following a mountain pine beetle epidemic in lodgepole pine stands in northern Utah. Vegetatio, 122, 1-12.

USDA Forest Service (2010). Major forest insect and disease conditions in the United States: 2009 update. Washington, D.C: Forest Health Protection.

Valbuena, R., Mauro, F., Jose Arjonilla, F., \& Antonio Manzanera, J. (2011). Comparing airborne laser scanning-imagery fusion methods based on geometric accuracy in forested areas. Remote Sensing of Environment, 115, 1942-1954. 
Walton, A. (2011). Provincial-Level projection of the current mountain pine beetle outbreak: update of the infestation projection based on the 2010 provincial aerial overview of forest health and the BCMPB model (year 8). BC Forest Service (15 pp., URL: http://www.for. gov.bc.ca/ftp/hre/external/! publish/web/bcmpb/year8/BCMP B.v8.B eetleProjection. Update.pdf accessed in November 2011)

Westfall, J., \& Ebata, T. (2011). 2010 Summary of forest health conditions in British Columbia. Victoria, British Columbia: British Columbia Ministry of Forests, Mines and Lands, Forest Practices and Investment Branch.

White, J. C., Wulder, M. A., Brooks, D., Reich, R., \& Wheate, R. D. (2005). Detection of red attack stage mountain pine beetle infestation with high spatial resolution satellite imagery. Remote Sensing of Environment, 96, 340-351.

Wood, S. N. (2011). Fast stable restricted maximum likelihood and marginal likelihood estimation of semiparametric generalized linear models. Journal of the Royal Statistical Society (B), 73(1), 3-36
Wood, S. N., \& Augustin, N. H. (2002). GAMs with integrated model selection using penalized regression splines and applications to environmental modelling. Ecological Modelling, 157, 157-177.

Wulder, M. A., Dymond, C. C., White, J. C., Leckie, D. G., \& Carroll, A. L. (2006). Surveying mountain pine beetle damage of forests: A review of remote sensing opportunities. Forest Ecology and Management, 221, 27-41.

Wulder, M. A., White, J. C., Carroll, A. L., \& Coops, N. C. (2009). Challenges for the operational detection of mountain pine beetle green attack with remote sensing. Forestry Chronicle, 85, 32-38.

Zhao, K., Popescu, S., \& Nelson, R. (2009). Lidar remote sensing of forest biomass: A scaleinvariant estimation approach using airborne lasers. Remote Sensing of Environment, $113,182-196$. 